\title{
THE PLATE ARCHIVE OF THE TAUTENBURG SCHMIDT TELESCOPE
}

\author{
R. ZIENER \\ Thüringer Landessternwarte \\ Karl-Schwarzschild-Observatorium \\ D-07778 Tautenburg \\ Germany
}

The Karl-Schwarzschild-Observatorium, about $15 \mathrm{~km}$ away from Jena in the Tautenburg forest at $330 \mathrm{~m}$ above sea level, was founded in 1960 . The $2 \mathrm{~m}$-Universal-Telescope contains three optical systems: Schmidt, Cassegrain and Coudé. The spherical primary mirror consists of Sitall (a Russian ceramic glass).

The Schmidt system with a free aperture of $1.34 \mathrm{~m}$ is the largest of the world. The focal length is $4 \mathrm{~m}$, and the vignetting-free field covers 3.3 degrees by 3.3 degrees on plates of $24 \mathrm{~cm}$ by $24 \mathrm{~cm}$. Colour filters are available for $U, B, V$, and $R$. The limiting magnitude on deep plates can reach $21.5 \mathrm{mag}$ in $B$ and $20.5 \mathrm{mag}$ in $\mathrm{V}$ and $\mathrm{U}$. A second corrector lens with an integrated prism is also available; this produces spectra with a reciprocal linear dispersion of 260 $\mathrm{nm}$ per millimetre at $\mathrm{H} \gamma$.

A multi-object fibre-feed spectrograph with robotic-positioning of 34 optical fibres in a field of 2.3 degrees diameter (Pitz et al. 1993) is under construction in cooperation with the Max-Planck-Institut für Astronomie Heidelberg.

More than 8300 plates have been taken with the Tautenburg Schmidt telescope since 1960. They are stored vertically in a room with temperature control.

The most important data of our plates have been available in computer-readable form since 1983. Now the catalogue is written in dBase IV and contains the following data:

$\begin{array}{ll}\text { - PLNR } & \text { plate number } \\ \text { - ALPHA } & \begin{array}{l}\text { right ascension of the plate centre } \\ \text { declination of the plate centre }\end{array} \\ \text { - DELTA } & \text { date of the beginning of exposure } \\ \text { - DATE } & \text { hour:minutes of the beginning of exposure } \\ \text { - BEGIN } & \text { exposure time } \\ \text { - ETIME } & \text { information on the emulsion-filter combination used } \\ \text { - EMFI } & \text { with or without calibration wedge } \\ \text { - W } & \text { remarks, e.g. objective prism plate } \\ \text { - REM } & \text { number for special objects, in most cases comets } \\ \text { - S } & \text { place of storage }\end{array}$

A short excerpt from the catalogue is given in Table 1. 
Table 1

\begin{tabular}{|c|c|c|c|c|c|c|c|c|c|c|}
\hline PLNR & ALPHA & DELTA & DATE & BEGIN & ETIME & EMFI & $\mathbf{W}$ & REM & $\mathbf{S}$ & PLACE \\
\hline 8263 & 11:24:11 & $+06: 30$ & 93MAR01 & 02:52 & 020:00 & B & 0 & BEWO & 0 & TAUTENE \\
\hline 8264 & $13: 41: 58$ & $+28: 24$ & 93MAR01 & 03:28 & 029:00 & B & 1 & & 0 & TAUTENE \\
\hline 8265 & 05:20:12 & $+42: 22$ & 93MAR19 & $20: 00$ & & OFUS & 0 & FOKAEBKA & 0 & TAUTENE \\
\hline 8266 & $03: 20: 27$ & $+41: 33$ & 93MAR19 & $20: 50$ & 022:00 & B & 1 & & 0 & TAUIENE \\
\hline 8267 & 08:40:11 & $+20: 01$ & 93MAR19 & 21:31 & 030:00 & B & 0 & & 0 & BABEI SE \\
\hline 8268 & 08:47:03 & $+21: 30$ & 93MAR19 & $22: 20$ & 029:00 & B & 0 & & 0 & BABEI SE \\
\hline 8269 & 09:57:49 & $+69: 11$ & 93MAR19 & 23:15 & 002:00 & B & 1 & & 0 & TAUTENE \\
\hline 8270 & $13: 41: 58$ & $+28: 24$ & 93MAR20 & $00: 10$ & 032:00 & B & 1 & & 0 & TAUTENE \\
\hline
\end{tabular}

Notes:

in EMFI: B, for blue plate with GG13 filter, OFUS, for blue plate without any filter;

in REM: the BEWO telescope is guided to a moving object,; FOKAEBKA focus plate for a special plate holder.

About 15 per cent of our plates have been loaned to 68 astronomers in various institutes all over the world. Unfortunately, some astronomers need 100 and more plates at the same time. Others have borrowed our plates for 10 years and longer. The largest problem is that some astronomers had loaned our originals to other colleagues, and we do not know now where the plates are. Analogous problems with their plate library seem to exist for the colleagues from the UKST (Morgan \& Tritton 1993). In accordance with the aims of the 'Wide-field Imaging' working group (MacGillivray 1993), we ask everyone who sees Tautenburg plates to help us by having the plates returned to our archive.

\section{References}

MacGillivray, H.T., 1993. Report of the 1st Meeting of the WFI WG Organising Committee, in IAU Commission 9, Working Group on 'Wide-field Imaging', Newsletter 2.

Morgan, D. and Tritton, S., 1993. UK Schmidt Telescope (UKST) News from ROE, in IAU Commission 9, Working Group on 'Wide-field Imaging', Newsletter 2.

Pitz, E., Lorenz, H. and Elsässer, H., 1993. The Tautenburg 'Feldspinne', in 'Fiber Optics in Astronomy' II, ASP Conference Series, Vol. 37, ed. P.M. Gray. 